\author{
Asian Journal of \\ Medical and Biological Research \\ ISSN 2411-4472 (Print) 2412-5571 (Online) \\ www.ebupress.com/journal/ajmbr
}

\title{
Article \\ Clinico-histopathological observations of pigeons (Columba Livia) suffering from Newcastle disease in northern Bangladesh
}

\author{
Md. Najmul Hassan Parvez ${ }^{1,2}$, Md. Reazul Islam³ ${ }^{3}$ Most. Tahera Dil Akter ${ }^{2}$ and Md. Jalal Uddin Sarder ${ }^{2 *}$ \\ ${ }^{1}$ Deartment of Anatomy \& Histology, Hajee Mohammad Danesh Science and Technology University, Dinajpur- \\ 5200, Bangladesh \\ ${ }^{2}$ Department of Veterinary and Animal Sciences, University of Rajshahi, Rajshahi-6205, Bangladesh \\ ${ }^{3}$ Department of Preclinical Courses, Faculty of Veterinary and Animal Sciences, Gono Bishwabidyalay, Dhaka- \\ 1344, Bangladesh
}

${ }^{*}$ Corresponding author: Professor Dr. Md. Jalal Uddin Sarder, Department of Veterinary and Animal Sciences, University of Rajshahi, Rajshahi-6205, Bangladesh. E-mail: jalalnusa@yahoo.com

Received: 07 March 2017/Accepted: 21 March 2017/ Published: 30 March 2017

\begin{abstract}
A survey was conducted to study clinical signs, gross and histopathological lesions in pigeons with naturally occurring Newcastle disease (ND). For this purpose, 45 pigeon farms of the Rajshahi, Natore and Pabna districts were conducted during from July 2015 to June 2016. Among these, 17(37.78\%) farms showed clinical signs of Newcastle disease, including mainly greenish white mucoid diarrhoea and nervous signs with high morbidity and mortality. Morbidity was $90 \%$ and mortality was $100 \%$. Diarrhoea, the most common clinical sign observed, was present in $48.28 \%$ of the affected pigeons, followed by nervous signs (27.59\%), shivering (24.14\%). Postmortem examination of affected birds showed lesions mainly in proventriculus, liver, lungs and kidneys. Histopathological changes were also observed in lungs, liver, and proventriculus. The results showed that the Newcastle disease virus was widespread in pigeons locally and caused high mortality rate. It is concluded that pigeon fanciers of northern Bangladesh do not maintain the regular preventive measures or vaccination against ND is being adopted to control the disease.
\end{abstract}

Keywords: pigeons; Newcastle disease; clinical signs; histopathology

\section{Introduction}

Pigeons are ubiquitous flying birds belonging to order columbiformes. The tradition of pigeon rearing in Indian subcontinent is traced back to Mughal era, when pigeons were primarily used as postal messengers. Now a days, domestic pigeons are commonly raised for racing, fighting and exhibition purposes in many cities of Bangladesh including Rajshahi. Moreover, the nutritional and therapeutic values of pigeon meat further enhance their utility. A variety of diseases affect pigeons but viral diseases predominate in terms of high morbidity and mortality. Newcastle disease (ND) is world wide in distribution and has a wide range of hosts like chickens, pigeons, turkeys, partridges, pheasants, doves, sparrows, gees, starlings and other free flying birds (Vindevogel et al., 1972). It is caused by avian serotype-1 paramyxovirus in pigeons that is closely related to paramyxoviruses causing ND in poultry but not identical (Alexander et al., 1985). The disease in pigeons is characterized mainly by sudden onset of listlessness, in-appetence, nervous manifestations and inability to fly. Morbidity and mortality averages 100 and 80\%, respectively (Eisa and Omer, 1984). Several outbreaks have been reported in pigeon lofts throughout the world including Sudan (Eisa and Omer, 1984), Continental Europe and Great Britain (Alexander et al., 1984), India (Mangat et al., 1988; Singh et al., 1989), Germany (Fischer, 1986), Pakistan(S. Shaheen et al., 2005 ) Turkey (Coven et al., 1999) and Japan (Maeda et al., 1987). Statistically it was found that pigeon diseases in northern Bangladesh comprises bactrial disease $(31.30 \%)$, viral disease $(43.70 \%)$, parasitic diseases $(9.43 \%)$ nutritional deficiency $(0.51 \%)$ and miscellaneous couses $(15.05 \%)$. Among the viral diseases 
Newcastle, Pigeon Pox and Papillomatosis comprises 12.58\%, 31.21\% and 0.08\%, respectively (Sarder et al., 2017). During the course of disease, the virus causes sub mucosal to ecchymotic hemorrhages in proventriculus. The urban population associated with keeping and breeding of pigeons usually possesses insufficient knowledge concerning the pathological and therapeutic aspects. Accordingly the health and husbandry matters of pigeons require particular consideration. A scarce information on clinical signs, gross and histopathological lesions of pigeon Newcastle disease in Northern Bangladesh is available. This manuscript describes these aspects in pigeons.

\section{Materials and Methods}

During July 2015 to June 2016, a total of 45 pigeon farms were randomly selected and visited in the research area of Rajshahi, Natore and Pabna districts. Among these, 17 farms showed clinical signs of Newcastle disease. None of the farms was vaccinated against ND virus. During the survey, prevalence of Newcastle disease in pigeons was evaluated. Clinical signs, morbidity and mortality rates were also recorded throughout the examination. The data was documented using a specially designed proforma for recording the number of birds, general history, management, previous disease, vaccination and treatment etc. Recently dead birds or birds showing peculiar clinical signs of ND were subjected to postmortem examination in the Diagnostic Laboratory, Department of Veterinary and Animal Sciences, University of Rajshahi. Gross lesions were recorded. Morbid samples from proventriculus, liver and lungs were collected and fixed in $10 \%$ buffered formalin for histopathological examination. These tissues were embedded in paraffin, sectioned and stained with Haematoxylin \& Eosin (Bancroft and Stevens, 1990).

\section{Results}

Forty five pigeon farms were visited, out of which 17(37.78\%) showed clinical signs of Newcastle disease. Surveys indicated that the onset of ND in pigeons was sudden. Affected pigeons showed in-appetence, listlessness and greenish white diarrhoea. Morbidity was $90 \%$ and mortality was $100 \%$. Diarrhoea, the most common clinical sign observed, was present in $48.28 \%$ of the affected pigeons, followed by nervous signs (27.59\%), shivering (24.14\%). Respiratory signs were not observed in any of the pigeon farms in the present study. Body condition of pigeons affected by ND was satisfactory in majority of the cases $(71.43 \%)$, however, $28.57 \%$ of the affected pigeons were emaciated. Most of the clinical signs observed during the study included twisting of head and neck (tremors) (Figure 1), greenish white mucoid diarrhea (Figure 2) and shivering. These signs along with respective percentages have been illustrated in Table 2 .

Postmortem examination of dead or clinically affected pigeons was conducted which showed gross lesions in various organs. Pale discoloration of liver in some pigeons. Kidneys in some pigeon were slightly enlarged. A few pinpoint haemorrhages were present in proventriculus of some pigeon (Figure 3). No gross lesions were detectable in other organs including trachea, esophagus, gizzard and intestines. Histopathologically, focal hepatitis, vacuolar degeneration was present in hepatocytes suggestive of mild degree of damage to liver tissue and congestion of the portal vein was present (Figure 8). Small to large multiple haemorrhages and congestion were seen in lungs (Figures $5 \& 6$ ). Mild degree of mononuclear cell infiltration was present (Figure 7). In the proventriculus, haemorrhage present at the tip of the gland (Figure 4).

Table 1. The prevalence of ND in the study area.

\begin{tabular}{llll}
\hline Location & No. of farms & Diseased farms & Prevalence (\%) \\
\hline Rajshahi & 15 & 6 & $40(\%) \mathrm{b}$ \\
Natore & 15 & 9 & $60(\%) \mathrm{a}$ \\
Pabna & 15 & 2 & $13.33(\%) \mathrm{c}$ \\
\hline
\end{tabular}

Table 2. Clinical sings observed in ND infected pigeons $(n=29)$.

\begin{tabular}{lll}
\hline Clinical sings & No. of birds & Percentage (\%) \\
\hline Diarrhoea & 14 & $48.28(\%)^{\mathrm{a}}$ \\
Nervous sings (Twisting of head \& neck) & 8 & $27.59(\%)^{\mathrm{b}}$ \\
Shivering & 7 & $24.14(\%)^{\mathrm{b}}$ \\
\hline
\end{tabular}

Values with different superscripts differ significantly $(\mathrm{P}<0.01)$. 
Table 3. Post-mortem lesions observed in ND affected pigeons $(n=29)$.

\begin{tabular}{lll}
\hline Organs & No. of birds & Percentage (\%) \\
\hline Proventriculus & 6 & $20.69(\%)$ \\
Liver & 6 & $20.69(\%)$ \\
Lung & 5 & $17.24(\%)$ \\
Kidney & 4 & $13.79(\%)$ \\
\hline
\end{tabular}

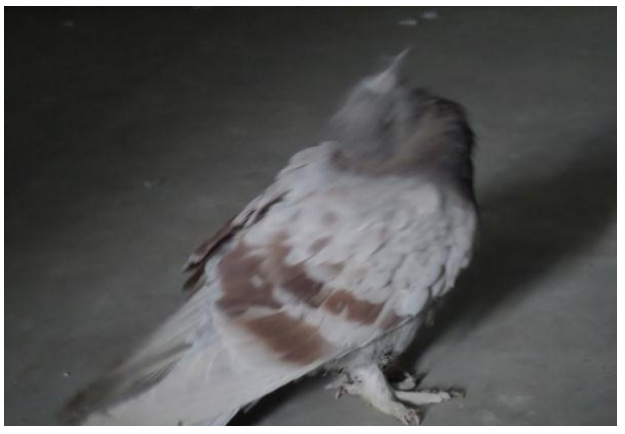

Figure 1. Twisting of head and neck due to ND.

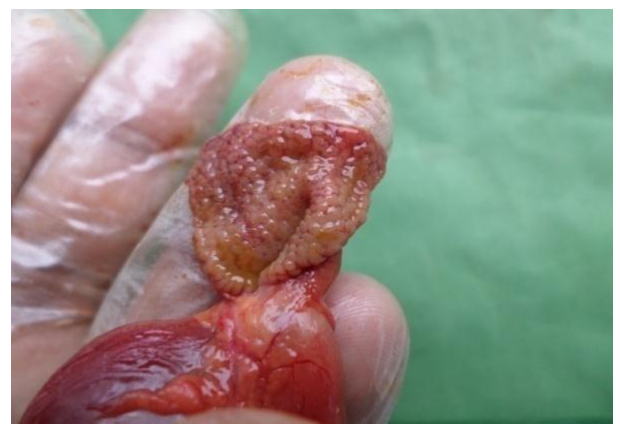

Figure 3. Pin point haemorrhage in the proventriculus in case of $\mathrm{ND}$.

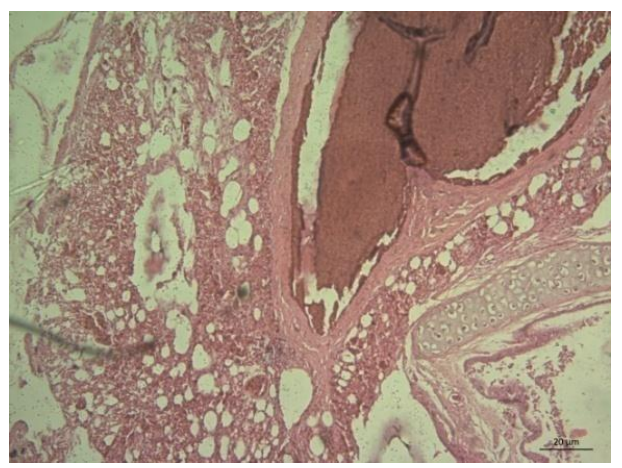

Figure 5. Congestion of the lungs (arrow) (H\&E x40).

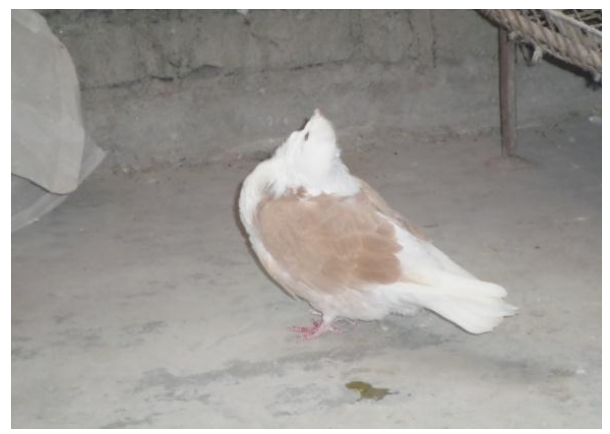

Figure 2. Diarrhoea and twisting of head symptom in case of $\mathrm{ND}$.

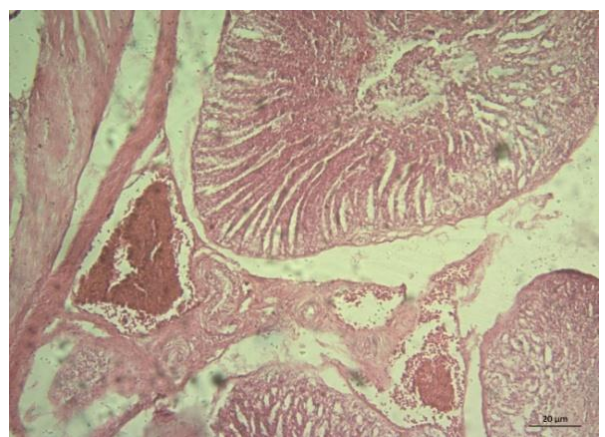

Figure 4. Hemorrhage present at the tip of the gland of proventriculus (arrow) (H\&E x40).

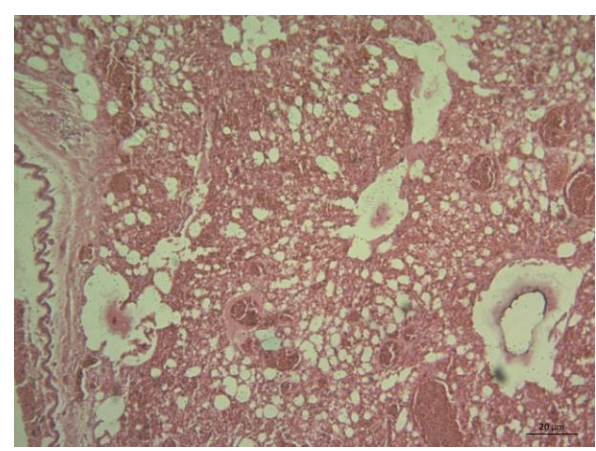

Figure 6. Hemorrhage and congestion of the lungs (arrow) (H\&E x10). 


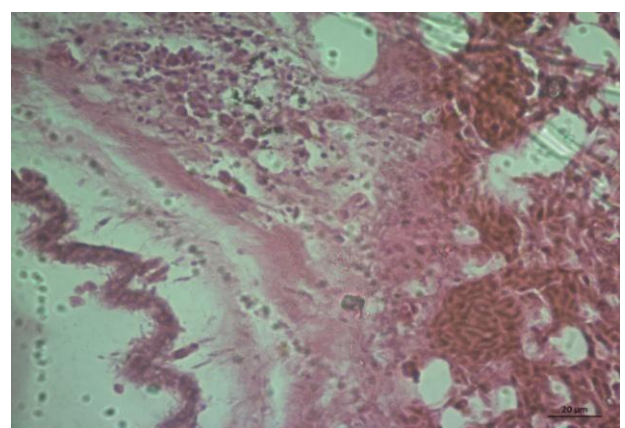

Figure 7. Infiltration of inflammatory cells (arrow) (H\&E x40).

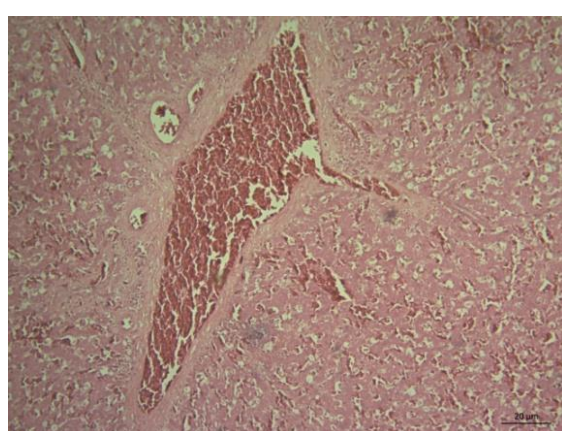

Figure 8. Focal hepatitis present, Congestion of portal vein (arrow) $(\mathrm{H} \& \mathrm{E} \times 10)$.

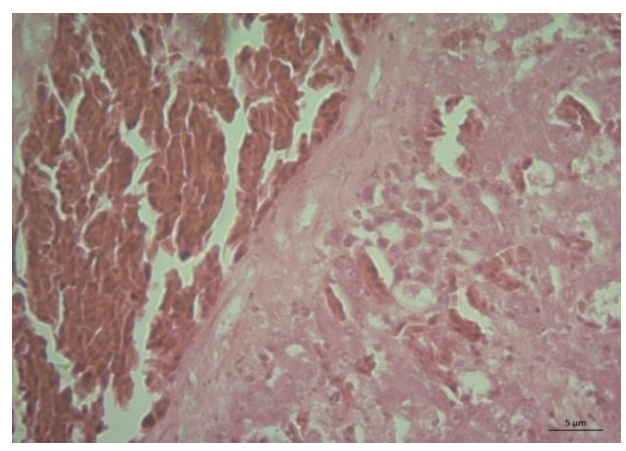

Figure 9. Infiltration of mononuclear cells (arrow) $(H \& E \times 40)$.

\section{Discussion}

Newcastle disease is a serious problem in pigeons. Fairly high morbidity $(90 \%)$ and mortality (100\%) rate due to paramyxovirus-1 (PMV-1) infection was observed in pigeons in the present study. Mangat et al. (1988) reported 50 to $70 \%$ morbidity in an outbreak of PMV-1 in racing pigeons in India. They further reported mortality around $60 \%$ in field outbreaks. During the study a survey of pigeon farms was conducted to determine the point prevalence of ND in pigeons in the research area. On the basis of green mucoid diarrhea and nervous signs it was considered that pigeons were suffering from ND. Using the mentioned clinical criteria, the point prevalence of ND in pigeons was observed to be 60\%, $40 \%$ and $13.33 \%$ in Natore, Rajshahi and Pabna district respectively. Observations of our study are correlated with the findings of Shaheen et al. (2005).

In the present study, greenish white diarrhoea and nervous signs were more frequently observed. Barton et al. (1992) also observed dirrhoea and nervous signs associated with ND in racing pigeons. In the present study nervous signs in $27.59 \%$ cases, diarrhoea in $48.28 \%$ and shivering in $24.14 \%$ cases were observed but Fischer (1986) observed nervous signs in $86 \%$ cases, diarrhoea in $18 \%$ and paralysis of legs and wings in $9 \%$ of naturally affected pigeons. Many other workers have reported similar signs of ND in pigeons in experimental (El-Mubarak et al., 1990; Mishra et al., 2000) and field outbreaks (Eisa and Omer, 1984; Tangredi, 1985; Fischer, 1986; Mangat et al., 1988). Khan (1968) reported paralysis of legs and wings in 80 and 60\% experimentally infected pigeons, respectively. The occurrence of paralysis and nervous signs reported by Khan (1968) are fairly high than those observed in Pakistan. The occurrence of paralysis of legs and wings were not observed in the present study. No respiratory signs were also observed in the present study. Khan (1968) did not observe any respiratory signs in field outbreaks or experimentally inoculated pigeons but laboured breathing and respiratory distress was reported in pigeons kept in a cage adjoining experimentally infected pigeons. In the present study, $71.43 \%$ affected birds showed satisfactory body conditions, while $28.57 \%$ birds were emaciated. However, it appears that body condition relates to the duration of the disease. Alexander et al. (1984) reported that general loss of condition and anorexia occurred occasionally in ND infected pigeons. According to Herdt and Devriese (2000), general condition of the pigeons remains well in ND. Gross lesions were present only in few cases in the present study. In this study lesions were also recorded in lungs, liver and proventriculus. In most cases no gross lesions were recorded. Eisa and Omer (1984) and Maeda et al. (1987) reported no gross lesions in natural outbreaks of ND in pigeons, while El-Mubarak et al. (1990) reported congestion of viscera and catarrhal enteritis in experimentally infected pigeons with paramyxovirus-1. Mubarak (2000) observed gross lesions and congestion in visceral organs in experimentally infected pigeons with chicken origin ND virus. 
Respiratory signs were not observed in present study which is in conformity to the findings observed by Herdt and Devriese (2000). They did not observe any respiratory signs in field outbreaks or experimentally inoculated pigeons. However, Fuller et al. (2010) reported the lack of gross lesions in natural ND outbreaks.

Histopathological changes were present in proventriculus, lungs and liver of the pigeons affected with ND in the present study. Mild degenerative changes were observed in liver in the present study. Fischer (1986) also observed mononuclear interstitial infiltration in liver in nearly all infected birds. However, Mangat et al. (1988) and ElMubrak et al. (1990) observed hepatitis. Although lungs appeared normal grossly, histological changes were detected including haemorrhages and mononuclear cell infiltration. Mubarak (2000) also observed haemorrhages and leucocytic infiltration in lungs but the type of leucocytes was not mentioned. Fischer (1986) did not observe haemorrhages but mononuclear interstitial infiltration was often seen in lungs of pigeons in natural outbreaks of paramyxovirus-1. No histological changes were detected in the trachea. It is concluded that the ND virus was wide spread in pigeons locally and no preventive measures or vaccination is being adopted by pigeon owners to control the disease.

\section{Conclusions}

From this study, it is concluded that due to high mortality rate Newcastle disease is an important harmful disease for pigeon rearing. Greenish white diarrhoea, head twisting and shivering are major clinical signs and grossly pin point haemorrhage in the proventriculus is the postmortem findings and microscopic study shows haemorrhage at the tip of the gland of proventriculus which is the key points for the diagnosis of ND. So, vaccination schedule should be applied regularly against ND for sustaining pigeon farm in Bangladesh.

\section{Acknowledgements}

The authors are grateful to the Department of Veterinary and Animal Sciences, Rajshahi University, Bangladesh for providing all essential facilities and to the Krishi Gobeshona Foundation (KGF), Bangladesh for financial support.

\section{Conflict of interest}

None to declare.

\section{References}

Alexander DJ, GWC Wilson, JA Thain and SA Lister, 1984. Avian paramyxovirus type-1 infection of racing pigeons: 3. Epizootiological considerations. Vet. Rec., 115: 213-216.

Alexander DJ, P Russel and G Parsons, 1985. Antigenic and biological characterization of avian paramyxovirus type-1 isolates from pigeons: An international collaborative study. Avian Pathol., 14: 365-376.

Bancroft JD and A Stevens, 1990. Theory and Practice of Histological Techniques. Churchill Livingstone, London, UK.

Barton JT, AA Bicford, GT Cooper, BR Carlton and CJ Cardona, 1992. Avian paramyxovirus type-1 infection in racing pigeons in California. Clinical signs, pathology and serology. Avian Dis., 36: 463-468.

Coven F, DJ Alexander, OZ Misirlioglu and I Ozdemir, 1999. A study of paramyxovirus-1 infection in pigeons. Bornova-Veteriner-Kontrolve-Arastirma-Enstitusu-Dergisi, 24: 1-10.

Eisa M, and E A Omer, 1984. A natural outbreak of Newcastle disease in pigeons in Sudan. Vet. Rec., 114: 297.

El-Mubarak AK, EEEA Elzein, AIA Elgasim, EME Abu Elzein and AIA Elgasim, 1990. Note on the pathology of experimental infection of pigeons by the pigeon paramyxovirus type-1 (PPMV-1). Revue-d'Elevage-etde-Med. Vet.Des-Pays-Tropica., 43: 441-444.

Fischer E, 1986. Pathology of spontaneous paramyxovirus-1 infection in pigeons. Inaugural Dissertation Fachbereich Veterinarmedizin JustusLiebig-Universitat, Giessen, German Federal Republic, pp. 84.

Fuller CM, L Brodd, RM Irvine, DJ Alexander and EW Aldous, 2010. Development of an L gene real-time reverse-transcription PCR assay for the detection of avian paramyxovirus type 1 RNA in clinical samples. Arch. Virol., 155: 817-823.

Herdt PD and L Devriese, 2000. Pigeons. In: Avian Medicine, by Tully, T. N., M. P.C. Lawton, G. M. Dorrstein (Eds.) Reed Educational and Professional Publishing Ltd. Oxford, UK, pp. 330

Khan MA, 1968. Epizootiology of Newcastle disease in wild birds. MSc. Thesis, Deptt. Microbiol., West Pakistan Agri. Univ., Lyallpur, Pakistan.

Maeda M, S Koizumi and M Yachi, 1987. Histopathological changes in Newcastle disease affecting racing pigeons in Japan. Japanese J. Vet. Sci., 49: 217-223. 
Mangat APS, G Singh and BS Gill, 1988. An outbreak of paramyxovirus encephalomyelitis in racing pigeons in India. Vet. Rec., 123: 496.

Mishra S, JM Kataria, RL Sah, KC Verma and JP Mishra, 2000. Pathogenesis of Newcastle disease virus isolates in pigeon. Indian J. Anim. Sci., 70: 1125-1126.

Mubarak A, 2000. Pathogenicity of Newcastle disease virus (chicken) in pigeons. MSc. Thesis, Deptt. Vet. Pathol., Univ. Agri., Faisalabad, Pakistan.

Sarder MJU, KMM Hossain and MH Islam, 2017. Pigeon diseases in northern Bamgladesh. World Poultry Science Association-BB, $10^{\text {th }}$ international poultry show and seminar, International convention city Boshundhara, Dhaka, 2-4 March., pp. 274-278.

Shaheen S, AD Anjum and F Rizvi, 2005. Clinico pathological observations of pigeons (Columba livia) suffering from Newcastle disease. Pakistan Vet. J., 25: 5-8.

Singh G, APS Mangat and BS Gill, 1989. Isolation of Newcastle disease virus (avian paramyxovirus-1) from pigeons (Columba livia) in India. Current Sci., 58: 154-155.

Tangredi BP, 1985. Avian paramyxovirus type-1 infection in pigeons: clinical observations. Avian Dis., 29: 1254-1255.

Vindevogel H, G Meulemans, P Halen and P Schyns, 1972. Susceptibility of the adult carrier pigeons to Newcastle disease virus. Ann. Res. Vet., 3: 519-532. 